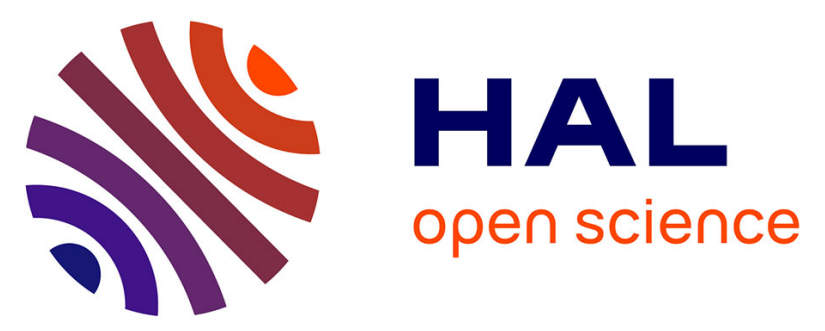

\title{
Behaviour model identification based on inverse modeling and using Optical Full Field Measurements (OFFM): application on rubber and steel
}

Vincent Velay, Laurent Robert, Fabrice Schmidt, S. Hmida, T. Vallet

\section{- To cite this version:}

Vincent Velay, Laurent Robert, Fabrice Schmidt, S. Hmida, T. Vallet. Behaviour model identification based on inverse modeling and using Optical Full Field Measurements (OFFM): application on rubber and steel. 10th ESAFORM conference on material forming, Apr 2007, Zaragoza, Spain. pp.33-38. hal-01703249

\author{
HAL Id: hal-01703249 \\ https://hal.science/hal-01703249
}

Submitted on 5 Mar 2019

HAL is a multi-disciplinary open access archive for the deposit and dissemination of scientific research documents, whether they are published or not. The documents may come from teaching and research institutions in France or abroad, or from public or private research centers.
L'archive ouverte pluridisciplinaire HAL, est destinée au dépôt et à la diffusion de documents scientifiques de niveau recherche, publiés ou non, émanant des établissements d'enseignement et de recherche français ou étrangers, des laboratoires publics ou privés. 


\title{
Behaviour model identification based on inverse modeling and using Optical Full Field Measurements (OFFM) : application on rubber and steel.
}

\author{
V. Velay, L. Robert, F. Schmidt, S. Hmida and T. Vallet \\ Research Centre on Tools Materials and Processes (CROMeP) \\ Ecole des mines d'Albi-Carmaux, 81013 ALBI Cedex 9, France
}

\begin{abstract}
Biaxial properties of materials (polymer or steel) used in many industrial processes are often difficult to measure. However, these properties are useful for the numerical simulations of plastic-processing operations like blow moulding or thermoforming for polymers and superplastic forming or single point incremental forming for steels. Today, Optical Full Field Measurements (OFFM) are promising tools for experimental analysis of materials. Indeed, they are able to provide a very large amount of data (displacement or strain) spatially distributed. In this paper, a mixed numerical and experimental investigation is proposed in order to identify multi-axial constitutive behaviour models. The procedure is applied on two different materials commonly used in forming processes: polymer (rubber in this first approach) and steel. Experimental tests are performed on various rubber and steel structural specimens (notched and open-hole plate samples) in order to generate heterogeneous displacement field. Two different behaviour models are considered, on the one hand, a MoneyRivlin hyperelastic law is investigated to describe high levels of strain induced in tensile test performed on rubber openhole specimen. On the other hand, Ramberg-Osgood law allows to reproduce elasto-plastic behaviour of steel on notched specimen. Each model identification is based on a same Finite Element Model Updated (FEMU) procedure which consists in comparing results provided by numerical simulation (ABAQUS ${ }^{T M}$ ) with full field measurements obtained by DISC (Digital Image Stereo-Correlation) technique (Vic $3 \mathrm{D}^{\circledR}$ ). In both cases, a cost function is defined minimizing in a least square sense the difference between experimental and numerical displacement fields induced into the structural specimen. In this paper, experimental tensile tests performed on rubber and steel specimen will be described, displacement and strain field measurements obtained by DISC technique will be analyzed. Then, the different steps of the methodology will be detailed. Displacement field calculated by numerical simulation will be available at each node of the FE meshing and will be properly associated to the experimental values measured by the optical full field method. Afterwards, these information will be useful to define the cost functions. Moreover, boundary conditions applied in the simulation, investigation area selected to perform identification, rigid body motion included in the experimental data and cost function forms will be discussed. Finally, results provided by the procedure will be presented for both investigated materials.
\end{abstract}

Keywords: Full field measurements, Forward problem, Behaviour identification PACS: $62.20 .-\mathrm{x}$

\section{INTRODUCTION}

The aim of this investigation is to present an original methodology able to determine multiaxial material properties. The approach can be applied to identify behaviour models of steels or polymers commonly used in many industrial forming processes like blow moulding or single point incremental forming. The paper is based on a mixed experimental and numerical approach using Optical Full Field Measurements (OFFM) and Finite Element model results. Today, this method is more and more applied in experimental mechanics, it allows to measure kinematic fields (displacement or strain) and provides extended possibilities to identify multiaxial behaviour models. Several recent investigations using different experimental full field methods and various identification procedures have been developed[1, 2]. In this investigation a Finite Element Model Updated (FEMU) method is considered[3, 4, 5]. It consists in comparing experi- mental measurements obtained by DISC (Digital StereoCorrelation) technique (VIC $3 \mathrm{D}^{\circledR}$ ) with numerical simulation (ABAQUS ${ }^{T M}$ ). Two different kind of tensile tests are investigated on two structural specimens and two materials (rubber and steel). The aim is to induce a multiaxial loading within the specimen, thus an open hole specimen is defined to investigate rubber behaviour whereas a notched specimen is investigated for steel behaviour.

\section{EXPERIMENTAL INVESTIGATION}

Both of tensile tests performed on rubber and steel have been carried out with a servo-electric testing machine and controller connected to a computer. It allows to measure the displacement rate and the global strength induced into the specimen. Two CDD cameras are located in front of the testing machine in order to measure dis- 
placement field during the tests by DISC technique (Figure 1).

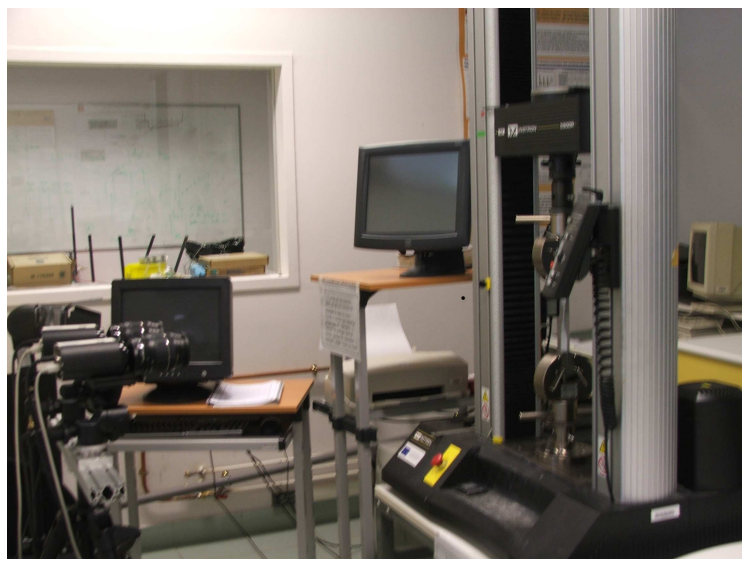

FIGURE 1. DISC set up and tensile testing machine

In each case, the investigation area only considers a part of the structural specimen and can not include the whole sample. This experimental method allows to provide displacement or strain field components induced within the investigation area by the global loading. Each displacement or strain map corresponds to a time increment of the tensile test. Figure 2 presents global tensile curve obtained for the steel specimen. In the following part, three images will be selected for the identification process corresponding to three time increments $(100 \mathrm{~s}$, 200 s and 300s). Similar assumption will be done for the rubber specimen.

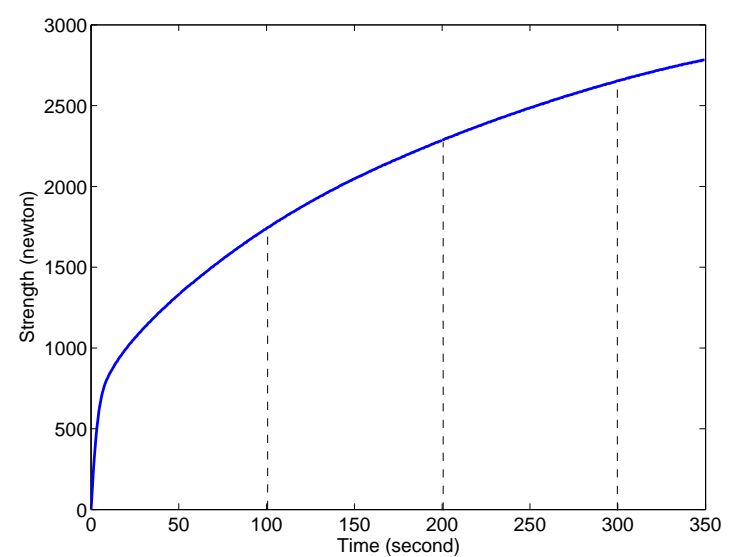

FIGURE 2. Tensile test performed on notched steel specimen

For instance, figure 3 shows axial and shear strain components within the steel notched specimen at a time of 300s. Kinematic field induces a rigid body motion will have to be taken into account into the identification process.
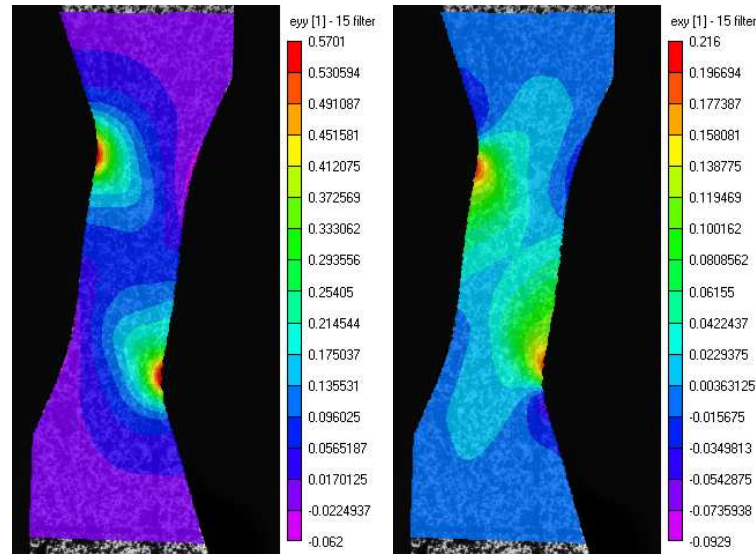

FIGURE 3. a- Axial strain field; b- Shear strain field measured by DISC Technique

\section{IDENTIFICATION METHODOLOGY}

\section{Strategy}

Identification strategy can be divided into several stages. First, some preliminary works have to be performed on the experimental files in order to keep only the correlated solutions and to avoid mismatched informations. Then, locations where experimental data are measured have to be projected onto the finite element mesh. Figure 4 presents for the rubber open-hole specimen a comparison between nodes considered in experimental and numerical meshes.

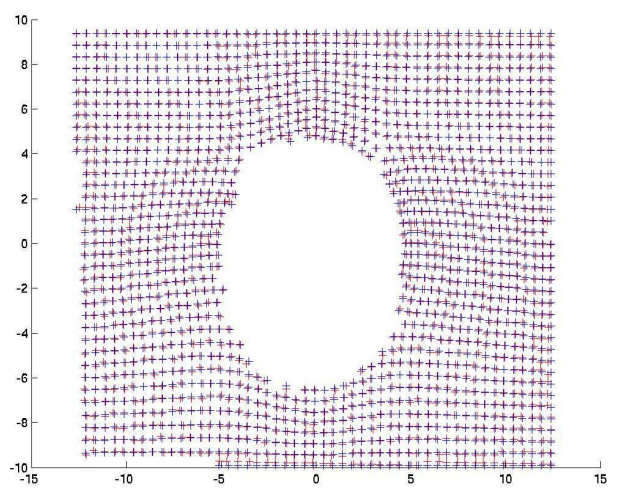

FIGURE 4. Finite element mesh projection onto experimental data

Only an investigation area is modelized in the numerical simulation. Experimental and calculated displacements will be considered to evaluate the cost function. Moreover, experimental displacements measured at the upper and lower parts of the specimen will be introduced into the simulation to define the boundary con- 
ditions. Thus, rigid body motions will be taken into account in the simulation. Finite element simulation will be performed with ABAQUS ${ }^{T M}$, a script allows to extract node displacements and global strength necessary to the analysis. The main program automatically runs the finite element calculation, extracts calculated and experimental data for the cost function evaluation and updates behaviour model parameters to be identified. Cost function minimization is performed with modified Nelder-Mead Simplex method implemented in Matlab ${ }^{\circledR}$.

The cost function depends on experimental and calculated displacements and strength. Its formulation includes a spatial (nodes) and time informations (images).

$$
J(P)=\beta \cdot \frac{\left\|u^{e x p}-u^{\text {sim }}\right\|}{\left\|u^{\exp }\right\|}+(1-\beta) \cdot \frac{\left\|F^{e x p}-F^{\text {sim }}\right\|}{\left\|F^{\exp }\right\|}
$$

where:

$$
\begin{aligned}
& \left\|u^{\exp }-u^{\text {sim }}\right\|=\sqrt{\sum_{k, i=1}^{N_{n}, N_{i}}\left(\left(u_{1}^{\text {sim }}-u_{1}^{\text {exp }}\right)_{k, i}^{2}+\left(u_{2}^{\text {sim }}-u_{2}^{\text {exp }}\right)_{k, i}^{2}\right)} \\
& \text { and: }
\end{aligned}
$$

$$
\left\|F^{\exp }-F^{\operatorname{sim}}\right\|=\sqrt{\sum_{i=1}^{N_{i}}\left(\left(F^{\text {sim }}-F^{\exp }\right)_{i}^{2}\right)}
$$

$N_{n}$ is the number of nodes considered for the analysis, $N_{i}$ the number of images obtained at various time increments, $u_{i}, i=1,2$ the displacement components, $F$ the global strength in the loading direction, $P$ the parameter vector to be identified and $\beta$ the weight parameter.

Figure 5a shows the calculated displacement magnitude field corresponding to the first image $(t=100 s)$. Applying the experimental displacement field as a boundary conditions (upper and lower parts of the specimen), rigid body displacement fields are naturally taken into account into the calculation. Figure $5 \mathrm{~b}$ illustrates reaction forces induced by the previous boundary conditions applied. They are considered for cost function evaluation.

\section{Behaviour modeling}

Two relevant laws are carried out in order to investigate rubber and steel behaviour. Indeed, a RambergOsgood law is considered to describe steel behaviour whereas a Mooney-Rivlin hyperelastic law is used to reproduce behaviour of rubber.

\section{steel}

A Ramberg-Osgood model is selected to reproduce the steel behaviour. This law is available into ABAQUS ${ }^{T M}$ software. Basic one-dimensional model is:
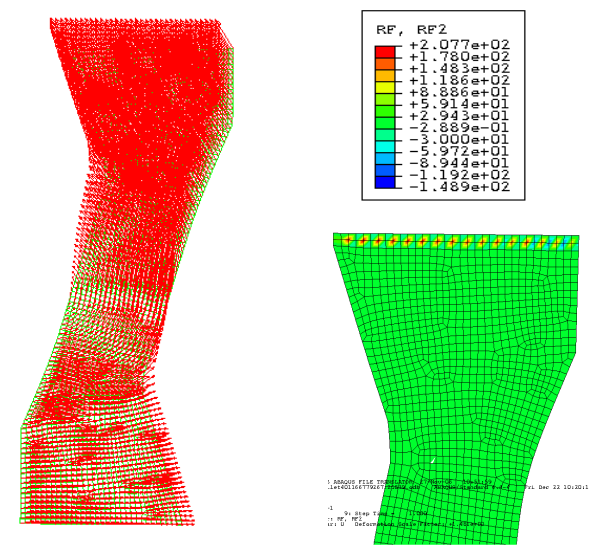

FIGURE 5. a- Displacement magnitude field induced in the steel notched specimen, b- Reaction forces induced by the boundary conditions

$$
E \varepsilon=E\left(\varepsilon_{e}+\varepsilon_{p}\right)=\sigma+\frac{E}{K}\left(\frac{|\sigma|}{K}\right)^{\frac{1}{M}-1} \sigma
$$

$E$ is the Young Modulus, $\varepsilon$ the total strain, $\varepsilon_{e}$ and $\varepsilon_{p}$ the elastic and plastic parts, $\sigma$ the stress induced, $K$ and $M$ the parameters of the non linear term defining the hardening.

Multiaxial formulation includes Hooke linear elastic relation used to generalize the first term of the previous equation and a nonlinear term to define plasticity through the use of the Mises stress potential and associated flow law.

$$
E \underline{\underline{\varepsilon}}=(1+v) \underline{\underline{\sigma}}^{\prime}-(1-2 v) p \underline{\underline{I}}+\frac{3}{2} \frac{E}{K}\left(\frac{\sigma_{e q}}{K}\right)^{\frac{1}{M}} \underline{\underline{\sigma^{\prime}}}
$$

Elastic properties $E$ and $v$ are assumed to be known and only both parameters of the nonlinear term $K$ and $M$ will be identified.

In order to assess the material parameters of the forward problem to be identified, various direct simulations have been performed in both cases (steel and rubber). Figure 6 presents evolution of the cost function versus the two parameters $K$ and $M$ of the Ramberg-Osgood law.

A global minimum seems to be reached around a value of 5 for $M$ and 500 for $K$.

\section{Rubber}

Mooney-Rivlin hyperelastic model is known to provide a good description of rubber behaviour. Moreover, it only requires two material parameters $C_{01}$ and $C_{10}$ to be identified. Energy function can be formulated as follow: 


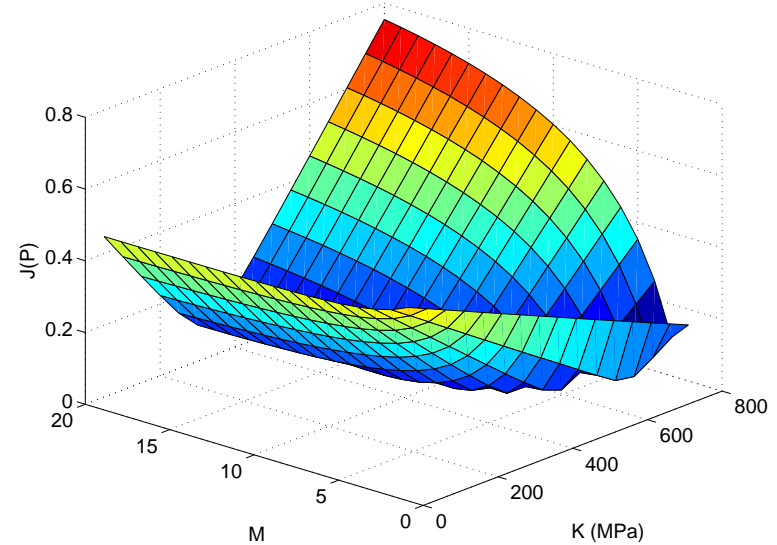

FIGURE 6. Evolution of the cost function versus the material parameters (Ramberg-Osgood law)

$$
W=C_{10}\left(I_{1}-3\right)+C_{01}\left(I_{2}-3\right)
$$

A multi-stage identification procedure is performed on a open-hole specimen. Figure 7 presents direct finite element simulation at different time increments.

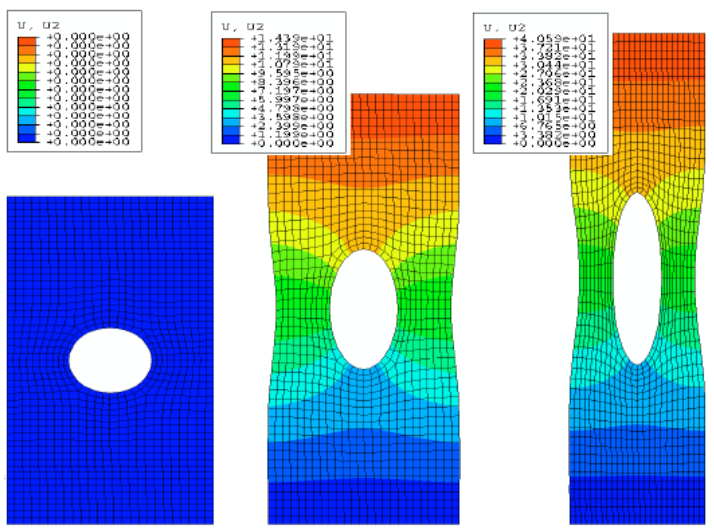

FIGURE 7. Displacement fields provided by a multi-stage numerical simulation performed on rubber open-hole specimen)

\section{Results and discussion}

For both cases (steel and rubber), preliminary tensile tests performed on flat specimens allows to assess a first set of material parameters and to initialize the identification procedure.

\section{Steel}

Several minimizations are performed in order to investigate the influence of the weight parameter $\beta$. A value of 0.9 confers a more important weight on the displacement field. On the contrary, a value of 0.2 allows to maximize the effect of the force induced. Figure 8 gives evolution of the Ramberg-Osgood parameters versus the number of iterations and figure 9 the evolution of the cost function for a weight parameter equals to 0.9 .

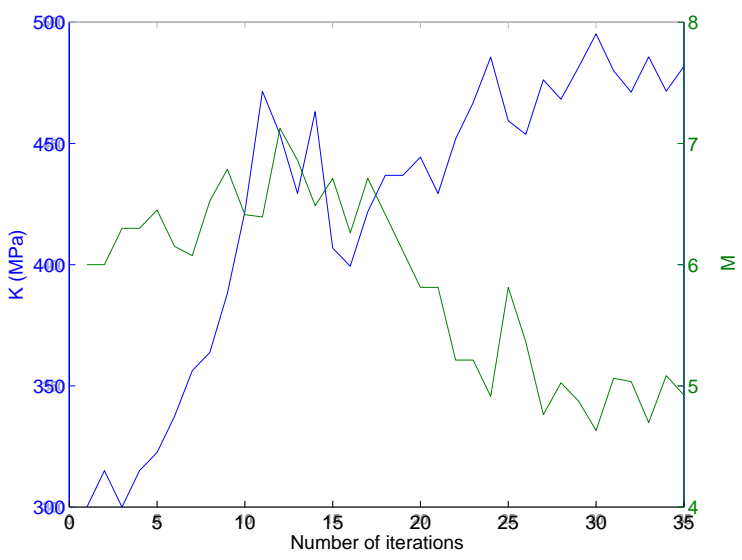

FIGURE 8. Evolution of the Ramberg-Osgood parameters $K$ and $M$ over the number of iterations for a weight parameter of 0.9

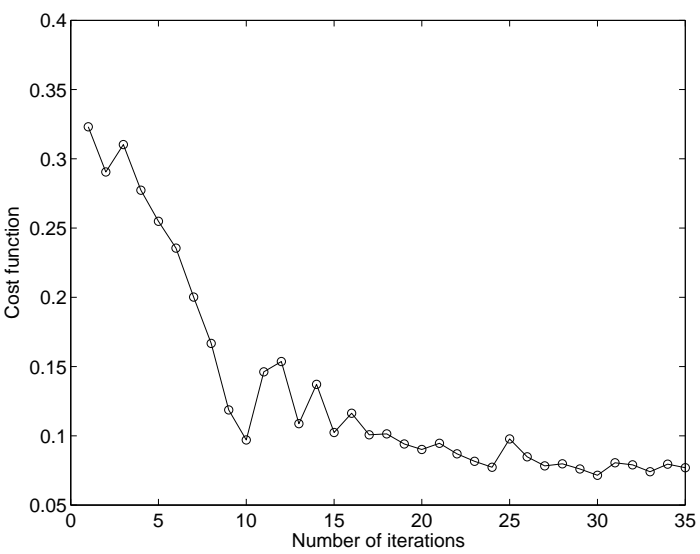

FIGURE 9. Evolution of the cost function over the number of iterations for a weight parameter of 0.9 and the RambergOsgood law

A good correlation on both displacement fields and reaction forces is obtained. Figure 10 presents axial (a) and shear (b) strain components for a time of 300s. Results can be compared with those provided by DISC technique (Figure 3). They are in a good agreement with experiment.

Table 1 gives presents final results. 

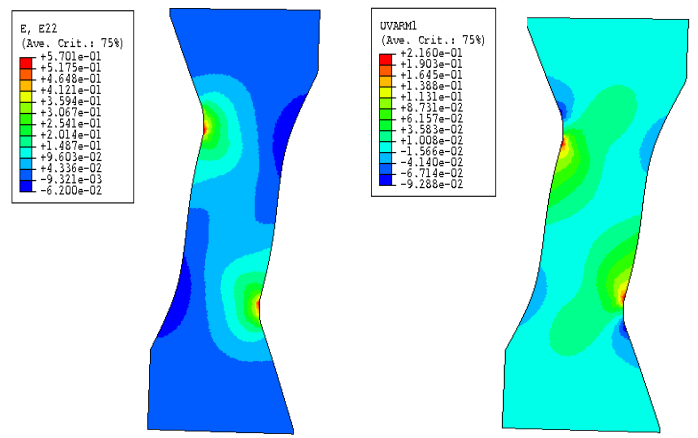

FIGURE 10. a- Axial strain field; b- Shear strain field calculated by Finite Element Simulation

TABLE 1. Final results provided by identification process $(\beta=0.9)$

\begin{tabular}{cccc}
\hline E MPa (fixed) & $v$ (fixed) & $K \mathrm{MPa}$ & $M$ \\
\hline 166000 & 0.34 & 481 & 4.92 \\
\hline
\end{tabular}

\section{Rubber}

In this case, DISC technique is more difficult to carry out due to the very large displacement induced in tensile tests. Presently, experimental results allow to assess the heterogeneous deformation within the specimen. But, these measurements can not yet be used to determine behaviour parameters by an inverse approach.

Figure 11 illustrates a comparison between measured and simulated shear strain field obtained with coefficients identified in uniaxial test conditions $\left(C_{10}=0.136\right.$ and $\left.C_{01}=0.097\right)$. Strain concentration can be predicted by optical measurements represented on only one half of specimen.
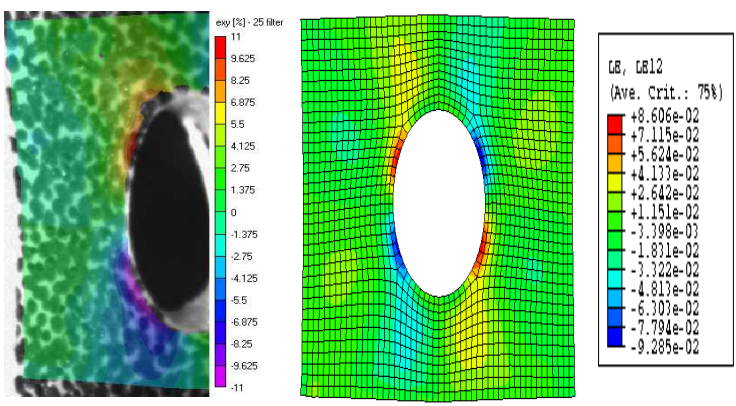

FIGURE 11. Comparison between experimental and calculated shear strain fields performed on open-hole rubber specimen

\section{CONCLUSIONS}

In this investigation, an efficient methodology was carried out in order to identify multiaxial behaviour laws within various test conditions and different materials. It is based on a forward problem using optical full field measurements and finite element simulations. For that purpose, a Finite Element Model Updated method was developed. A cost function was formulated in term of displacement fields and reaction forces and minimized by a modified Nelder-Mead Simplex algorithm. Two different applications were considered. On the one hand, identification of elastoplastic behaviour law of steel was successfully performed. Strain component fields provided by numerical simulation are in a good agreement with those obtained from an experimental point of view. On the other hand, the inverse approach was applied on a hyperelastic behaviour of rubber. In this case, some experimental problems occur. Test conditions have to be improved in order to be able to perform a complete multiaxial identification.

\section{REFERENCES}

1. M. Meuwissen, An inverse method for the mechanical characterization of metals, Ph.D. thesis, Eindhoven university of technology (1998).

2. M. Bonnet, M. Grédiac, F. Hild, S. Pagano, and F. Pierron, Mécanique et Industries 11, 297-305 (2003).

3. H. Haddadi, S. Belhabib, M. Gaspérini, and P. Vacher, "Identification of the parameters of Swift law using strain field measurements," in $8^{\text {th }}$ European Mechanics of Materials Conference, Conference on Material and structural identification from full-field measurements, Cachan, France, 2005.

4. M. Giton, A.-S. Bretelle, and P. Ienny, Strain 42, 291-297 (2006).

5. D. Lecompte, A. Smits, H. Sol, J. Vantomme, and D. V. Hemelrijck, "Elastic orthotropic parameter identification by inverse modeling of biaxial tests using Digital Image Correlation," in $8^{\text {th }}$ European Mechanics of Materials Conference, Conference on Material and structural identification from full-field measurements, Cachan, France, 2005 